\title{
Weaving an Innovation Network from the Middle Out: the Case of the Renewable Energy Ecosystem
}

\author{
Tali Zohar ( $\nabla$ talina.nave@gmail.com ) \\ University of Haifa \\ Yael Parag \\ Interdisciplinary Center Herzliya \\ Ofira Ayalon \\ University of Haifa
}

\section{Research Article}

Keywords: middle-out, innovation ecosystem, actor networks, technology push, market pull

Posted Date: November 30th, 2021

DOI: https://doi.org/10.21203/rs.3.rs-1106779/v1

License: (1) This work is licensed under a Creative Commons Attribution 4.0 International License.

Read Full License 


\section{Abstract}

\section{Background}

Renewable energy (RE) systems are becoming a central component of the clean energy transition and often seen as the way to combat climate change. Their establishment requires innovation, investments, and deployment policies for emerging technologies. Governments around the world are increasingly trying to create and support the energy-tech and climate-tech innovation ecosystems in their attempt to promote an innovation-supporting environment. However, energy innovation policies are often aligned with the dichotomous notion of technology-push and market-pull, and overlook the social, political, and cultural contexts in which RE innovative technologies are embedded, and the multiple actors and interactions that are associated with their development. By combining the Middle-Out Perspective (MOP) and innovation literature, this paper argues that an innovation ecosystem could be weaved from the middle-out.

\section{Methods}

This paper analyses the case of Israel's RE innovation ecosystem creation through the lens of the MOP and applies a socio-technical interpretation to the push and pull terminology. Process tracing methodology was applied to trace a sequence of events to determines whether an actor was pushed or pulled, the formation of a network of actors, and its evolvement to an energy innovation ecosystem from the middle-out. Data for the analysis was collected from interviews, policy papers, media articles and Governmental decisions.

\section{Results}

The analysis demonstrates how middle actors push the implementation of RE technologies in Israel, and at the same time pull decision-makers and other middle actors to promote the low carbon transition. The push and pull forces and the interactions between actors lead to the engagement of new stakeholders in the innovation network, the adoption of more ambitious RE targets and supporting policies, and to the creation of an effective RE innovation ecosystem.

\section{Conclusions}

This paper uses the MOP as an analytical framework and the push and pull terminology to demonstrate how a middle actor initiates and develops an actor-network by interacting with other actors. As this network broadens, it forms an effective innovation ecosystem. Network of actors have the potential to lead change, provide innovative ideas, initiate research, encourage investments, create employment possibilities, and promote regional sustainable development.

\section{Introduction}


New technologies and innovation are often seen as the best way to combat climate change [1,2]. Renewable energy (RE) systems and their derivatives - including production, infrastructure, storage, and management technologies - are becoming a central component of the clean energy transition, and their establishment requires innovation, investments, and deployment policies for emerging technologies [35]. Ideally, innovation-friendly governance should endorse climate protection, encourage competition in developing new products, create new markets, strengthen the economy and generate job opportunities [6, 7].

The emergence of innovation is often described as a linear sequence in which a product stems from research labs, is then developed, commercialized, and diffused to the market by an industry ('technology push'), or as an invention that is proposed or developed as a solution to an identified new market needs ('market pull'). In practice, market-pull and technology-push are matched when a need and a solution emerge simultaneously. This matching is critical for mainstreaming innovation [7-12]. However, the assumption that innovation results from coupling new technologies and market demand overlooks the social, political, and cultural contexts in which this process takes place. The contextual aspects of RE innovation include elements such as public awareness of environmental problems and resource exploitation, as well as concerns regarding health hazards linked to different RE systems $[13,14]$. The linear push and pull perspective does not pay sufficient attention to the various components that are associated with innovation development [8].

The 'systems of innovation' approach, which emerged in the mid-90s [15-21], perceives innovation as initiated and shaped by the 'systemic' interactions between multiple actors, institutions, research, and technical change. It presents the emergence of innovation as a horizontal prism, rather than the narrow and vertical focus of technology-push and market-pull [22]. Thus, innovation is recognized as a multilayered network that assembles different actors (including, for example, academic institutions, commercial corporates, investments funds, professionals, policymakers) from different levels (local, regional, national), joined by the mutual goal to enable a change or sectoral development, and which eventually creates an innovation ecosystem [23-26].

Governments around the world are increasingly striving to create and support clean-tech, energy-tech, and climate-tech innovation ecosystems to promote an innovation-supporting environment [27]. However, current energy innovation policies are still very much aligned with the dichotomous notion of technologypush and market-pull and its underlying logic that supply-side leads to demand-shift, and influences both the area where innovation is needed and the timeline of innovation emergence $[8,28,29]$. This logic leads to top-down induced incentives for energy innovation, such as motivating "carrots" and penalizing "sticks" in the forms of government-supported Research and Development (R\&D), Feed-in-Tariffs (FiT), subsidies, tax credits, or rebates for consumers [30-36]. It ignores, however, broader elements that influence the spread of innovation, such as skills and training, and the role of prototyping and demonstration. It also overlooks the fact that all technologies, including RE technologies, are improving continually and these improvements affect the whole energy system [27]. 
Various actors aside from governments are operating in the arena of RE innovative technologies, including non-governmental organizations (NGOs), professional organizations, commercial firms, local municipalities, and others. These actors are filling an active role in the development and implementation of innovation. They support many innovative initiatives by, for example, offering funding, providing a field for experimentation, creating regional hubs, supporting energy cooperatives, or declaring carbon neutrality zones [37-42]. Their roles extend beyond the aspects directly related to technology development, as they also provide innovative ideas and serve as knowledge brokers, watchdogs, lobbyists, and representors of marginal voices [37, 43-45]. As such, these actors are essential players in the innovation network and participate in the low carbon transition, and often fill a lead role in it.

Those actors participating in the transition network are considered by the Middle Out Perspective (MOP) as middle actors. The MOP $[46,47]$ is an analytical framework used to understand how socio-technical changes happen. It focuses on middle actors that are positioned in-between the policymakers at the top and the energy users at the bottom. Because they have assets and resources, middle actors can diffuse their agendas, knowledge, and experience in a middle-out manner: upwards (to influence policymakers), downwards (to influence citizens and end-users) and sideways across their networks (to influence other organizations, companies, and actors located in between the levels).

Although financial policies associated with technology-push and market-pull fail to address the complexity of innovation processes and the creation of an innovation network of actors, it is useful to examine the innovation process using the push and pull terminology. The push and pull concepts capture the balance of forces affecting the co-dependent relationships between the various actors, facilities, institutions, funds, and knowledge, which together compose the innovation ecosystem. Therefore, this paper proposes a socio-technical interpretation of the push and pull terminology within the MOP context: while middle actors driven by economic considerations, needs, environmental values, social norms, and ideology, are 'pushing' the implementation of RE technologies, they are also 'pulling' by decision-makers and other middle actors towards a socio-technical low carbon transition. The push and pull forces and the interactions between actors lead to the engagement of new stakeholders in the innovation arena and weave a network that creates an effective innovation ecosystem.

This study follows the evolution and roles that the local public benefit corporate 'Eilat-Eilot Renewable Energy Initiative' (hereafter, Eilat-Eilot) has played in the creation of the Israeli RE innovation ecosystem. Eilat-Eilot is located in the south of Israel and was established in 2002 by two neighboring local municipalities. Despite its peripheral location, low socioeconomic status, the lack of supportive national climate policy, and insufficient RE supporting regulation, Eilat-Eilot set itself an ambitious goal to promote regional clean energy self-sufficiency by 2025 , and to become a leader in the development of low-carbon innovative technologies.

Using the MOP as an analytical framework and the push and pull terminology, our analysis (1) Demonstrates the middle actor role played by Eilat-Eilot in initiating and strengthening an innovation network to promote sustainable local development; (2) Traces the push and pull forces between Eilat-Eilot 
and policymakers and shows how Eilat-Eilot activities challenged the unambitious national targets and contributed to Israel's RE energy policy; and (3) Follows the formation of RE innovation ecosystem and highlights its contribution to the development and implementation of RE in Israel.

Most of the MOP research to date has focused on middle actors' impact on top and bottom actors. Much less attention has been given to the sideway impact, i.e., the impact of middle actors on other actors located between the top and bottom [48]. Tracing the activities by which a middle actor initiates and develops a network of actors sheds light on this less studied MOP aspect - the sideways impact. The case study demonstrates the need for a network composed of many top, bottom, and middle actors to effectively promote innovation in general, and in the RE area in particular. By combining the MOP and innovation literature, this paper argues that an innovation ecosystem could be established from the middle out. This insight has practical implications for the EU RE promotion policies. The EU seeks to strengthen local governments and local communities and to promote their social and environmental resilience by relying on sustainable and local assets and resources $[49,50]$. Local climate mitigation solutions and social resilience could be gained by innovation or policies that are suitable for the local socio-technical conditions, and which local governments are familiar with. Hence, while this paper focuses on a case study from Israel, the insights from the phenomena it demonstrates - the creation of effective innovation promoting networks - are relevant to other places in which the local government's targets are more ambitious than those of the central government.

The paper begins with a short introduction to the MOP followed by a description of Israel's RE policy and the research method. Next, we present the findings, which track the development of the Eilat-Eilot network between 2002-2020 and the impact it had on the RE innovation ecosystem and the RE sector in Israel. The paper concludes with some policy recommendations.

\section{The Middle-Out Perspective}

The transition to a low carbon energy system is often seen as a process induced by policymakers through regulation and economic incentives in a top-down manner, or by local organizations and civic pressure in a bottom-up manner. The MOP suggests that there is a 'middle' layer of active and influential actors between the policymakers at the top and the citizens at the bottom. Policymakers ignore many of these middle actors as they are not perceived as having any official role in the transition $[46,47]$. The groups of middle actors include a variety of for-profit and non-profit organizations, communities, groups of professionals, and institutions that contribute to a systematic durable change of the energy system [47, $48,51-58]$. The MOP argues that due to their position between the top and bottom and their connections with actors positioned at the top and bottom, middle actors can influence in three directions - upwards on government officials and regulators, downwards on end-users and citizens, and sideways on peers and similar organizations and actors. The strength of middle actors stems from their perception as reliable and legitimate by other actors in the policy domain, and from their unique qualities which other actors in the system are short of or lack, such as tacit knowledge and skills, unique access to financial resources 
and other assets, social and professional legitimacies, and unique communication channels $[46,47]$. Previous studies which applied to the MOP in the field of energy and the field of public health demonstrated how middle actors fill the functions of (1) aggregators of assets and financial resources, thus supporting and coordinating valuable actions; (2) mediators between policymakers and the public, thus making relevant information and regulation accessible to the public, and at the same time reflecting the public's needs and concerns to policymakers; and (3) enablers of actions by having the knowledge and capability to tackle physical, technical and bureaucratic difficulties $[46,59,60]$.

The MOP also suggests that an actor with high levels of agency and capacity can derive a durable change. Agency indicates an actor's motivation, interest, and willingness to act in order to achieve a certain goal, and is shaped by social norms, culture, common practice, and regulation. Capacity indicates the actor's capability to execute the actions it wishes to perform, and is affected by external factors (such as physical and technical abilities, existing infrastructure, and available technologies), as well as internal factors (such as financial means, knowledge, and expertise) [47, 48, 61-63]. Middle actors have the unique qualities and assets necessary to elevate the levels of agency and capacity of other actors in the policy arena - at the top, middle and bottom - thus increasing the likelihood for a durable change to occur [47].

Previous research demonstrated how various middle actors, including religious congregations [47] building professionals [46, 53, 54, 60, 64-66] local communities [61, 67], businesses [48] and social groups $[57,59]$ performed middle-out strategies and promoted the transition to a low carbon society in various ways. These studies focused mainly on the influence on top and bottom actors. Other studies followed the mechanisms of influence in the fields of RE and electric vehicles [48]. Here, we emphasize the sideway mode of actions and the sideway impacts and highlight how middle actors establish an actor-network by interacting with other actors. As this network broadens, it forms an effective innovation ecosystem.

\section{Israel's renewable energy status: unambitious targets and lagging implementation}

In 2020 , the Israeli electricity fuel mix included $70 \%$ natural gas, $24 \%$ coal, and only $6 \%$ RE. By 2025 , Israel intends to phase out coal, increase the production and dependence on natural gas to nearly $80 \%$, and increase renewable production to $21 \%$ [68]. Approximately $55 \%$ of Israel's GHG emissions are associated with electricity production [69], more than transportation, industry, and agriculture combined. Therefore, meaningful mitigation strategies should focus on the transition to low carbon and renewable-based electricity generation [70]. However, while improving Israel's energy independence, the discovery of major natural gas reserves strengthens Israel's dependency on fossil fuels, and some argue that it delays the decarbonization process [71-73]. 
Unlike other countries that are members of the Organization for Economic Co-operation and Development (OECD), Israel National Determined Contributions (NDCs) to reduce national emissions and adapt to the impacts of climate change are moderate and unambitious [74]. In addition, the pledge to reduce emissions is on a per capita basis (from 10.4 to 7.7 million tons $\mathrm{CO}_{2}$ e per capita by 2030) but due to Israel's high birth rate, the per capita reductions will be compensated by population growth, thus Israel is not expected to reduce its overall emissions at all [75].

Israel is already experiencing climate change effects such as rising minimum and maximum temperatures, sea-level rise, and more frequent extreme weather events, including prolonged droughts and floods [74]. It undoubtedly needs to formulate effective climate adaptation policies, while contributing to the world's mitigation efforts to transition to a low carbon society [71].

Four types of renewable sources are suitable for Israel's conditions: the most prominent and applicable one being solar (PV and thermo-sola), followed by wind, biomass, and biogas [76]. However, a combination of economic and political factors, rather than concerns regarding climate change, have influenced Israel's RE targets. These factors include the cost of technology and the financial support required by the state for early adopters, as well as the aspiration to become a member of the OECD and ratify the Paris Agreement [77]. Over the years, Israeli Governments have made several decisions regarding the production of electricity from RE sources [78]. Table 1 summarizes four governmental RE targets that were set over 20 years, between 2002-2021, and the actual RE production.

\section{Table 1: RE Governmental Decisions 2002-2021}

\begin{tabular}{|c|c|c|c|}
\hline $\begin{array}{l}\text { Decision } \\
\text { No. }\end{array}$ & Year & Production Target & Actual Production \\
\hline \multirow[t]{3}{*}{2264} & 2002 & $2 \%$ by 2007 (and 1\% increase every three years) & \\
\hline & & $5 \%$ by 2016 & \\
\hline & & $10 \%$ by 2020 & \\
\hline \multirow[t]{2}{*}{4450} & 2009 & $5 \%$ by 2014 & $0.1 \%$ in 2009 \\
\hline & & $10 \%$ by 2020 & \\
\hline 3484 & 2011 & $\begin{array}{l}\text { Quotas have been set for the production of renewable } \\
\text { energy from solar energy, wind, biomass, biogas, and } \\
\text { waste }\end{array}$ & $\begin{array}{l}\text { Until this resolution, } \\
\text { no RE policy was } \\
\text { set }\end{array}$ \\
\hline \multirow[t]{2}{*}{542} & 2015 & $13 \%$ by 2025 & $1.9 \%$ in 2014 \\
\hline & & $17 \%$ by 2030 & \\
\hline \multirow[t]{2}{*}{465} & 2021 & $20 \%$ by 2025 & $6 \%$ in 2019 \\
\hline & & $30 \%$ by 2030 & $9 \%$ in 2020 \\
\hline
\end{tabular}


Although the first governmental target regarding RE generation was set in 2002, supporting policies or implementation strategies were not issued until 2011. In 2008, the Electricity Authority (the Israeli electricity regulator) allocated quotas for RE generation and provided FiT for each type of technology. Meeting these quotas was challenging because of the lengthy and complex facility planning process and permit approval procedures, and because the involvement of numerous stakeholders slowed down the construction process of the RE facilities [78-80]. The quota system was criticized by the State Comptroller as inadequate, and a 2012 governmental committee that examined the economic viability of integrating RE facilities recommended changing the quota system. However, only in early 2017, when the technology costs dramatically declined (mainly PV), the Electricity Authority moved to a price tenders' method. The Electricity Authority also made significant efforts to ease the bureaucratic processes [78].

Often, the reluctance of the Israeli government to sponsor new technologies inhibits the advancement of innovative proven technologies that are in their early deployment stages but are still expensive and therefore require financial support. In the RE field, this results in a bias against smaller facilities in urban areas, such as rooftops on commercial and public buildings, in favor of large projects over open lands [80]. However, years of low investments in transmission lines have led to insufficient transmission capacity, which does not support the operation of new large RE facilities in most areas of the country [81]. Improving the transmission infrastructure to accommodate distributed RE generation could take 5-15 years and this is likely to slow the pace of new RE installation and make Israel's goal of 30\% RE by 2030 hard to achieve [82]. Recent policy papers suggest that energy storage in the existing transmission network could enable the connection of additional RE facilities in the near future, even before new transmission lines are built [81, 83].

While the RE generation in Israel is lagging behind many other OECD countries, the RE industry is positioned at the forefront in terms of innovation and groundbreaking technologies. However, bureaucratic barriers in the processes of allocation and licensing pilot and demonstration facilities, as well as financial difficulties, prevent the implementation of local innovative solutions in Israel, and inhibit their penetration to the international market [84].

\section{Methods}

\section{Data collection}

To follow the development of the network of actors and to examine the unique contribution of Eilat-Eilot to the formation of the Israeli energy innovation ecosystem, data was collected from various sources using different methods:

Interviews: Nine semi-structured interviews were conducted with personnel from organizations at the top and the middle of the Israeli energy arena, including the Israeli Electricity Authority (two interviews) and Ministry of Energy (one interview), the Steering Committee of the strategic plan for a low-carbon economy in Israel 2050 (one interview), Eilat-Eilot officials (two interviews), local renewable energy entrepreneurship 
(two interviews) and Federation of Local Authorities in Israel (one interview). All the interviews lasted approximately one hour and were audio-recorded (with informed consent) and transcribed.

Documents: various documents were reviewed, including 50 articles that were published online in newspapers and the economic press, covering Eilat-Eilot development between 2002-2020; 10 minutes of different Israeli Parliament's committees that discuss RE policy, implementation, and the associated barriers; 6 governmental decisions related to RE; 12 reports that address Israel's climate and energy policy and the future of the energy sector.

Websites: various websites were reviewed, includingEilat-Eilot; Eilat Municipality; Eilot Regional Council; Capital Nature.

\section{Data analysis}

Process tracing methodology $[85,86]$ was applied in this study to analyze the data. This methodology is commonly used for qualitative analysis, mainly in political and historical studies, as it enables the researcher to trace a sequence of events and to determine whether there is a circumstantial connection between specific actions and the resulting outcomes [87-89]. A detailed and rich description allows the researcher to follow a narrative within a case study and to link theory with empirical work $[89,90]$ and to answer questions such as: Was it an Eilat-Eilot activity that pulled policymakers to set a specific regulation? Did a specific government call for action push Eilat-Eilot to act?

In the analysis, the historical sequence of governmental activities and Eilat-Eilot activities are described, with an emphasis on the time in which governmental discussions took place, decisions were made, and regulations were set. In parallel, the layout of the various activities that were taken by Eilat-Eilot during the examined period is presented. Along this timeline of activities, new actors that joined the Eilat-Eilot network are recognized, and their active contribution is acknowledged.

To establish a regulatory outline and identify barriers to the implementation of RE, public statements, governmental decisions, and other publications were reviewed. Articles from newspapers, websites, and policy documents were used to trace and establish push and pull forces between Eilat-Eilot and the various officials that were acting at that time. Lists of participants in professional forums, conferences, and courses were followed to track the formation process of the network, as well as media articles. Findings were complemented by input from the interviews.

The sequence of events determines whether an actor was pushed or pulled. For example, Eilat-Eilot is considered as pulling others if it initiated an activity to which the government or other actors in the arena corresponded. It is considered as being pushed if it had acted or made a decision in correspondence to other actors' actions. By using the process tracing methodology, we can identify the push and pull forces that shape RE decisions and determine if and how Eilat-Eilot influenced Israel's energy policy and 
regulation. We can also follow the progress toward the Eilat-Eilot regional goals while tracking the formation of the network, and its evolvement to an energy innovation ecosystem.

\section{Results}

\section{In the middle: The 'Eilat-Eilot Renewable Energy' initiative}

The southern region of Israel (also referred to as the Southern Arava region[1]) is arid with high solar radiation. It is located at the edge of the national electricity grid and suffers from under-maintained electricity infrastructures that have significant transmission losses. As a result, when electricity demand is higher than usual, a polluting oil-fueled substation in the city of Eilat is switched on.

Located on the Red Sea coast, Eilat's main source of income is local and international tourism. Hotels, restaurants, and other hospitality activities use air-conditioning around the clock during summer.

Eilot Regional Council is adjacent to Eilat. It accounts for $13 \%$ of the total land of Israel with only 4,500 residents living in 12 settlements, 10 of which are Kibbutzim, which are rural settlements relying on agriculture as a primary source of income.

Between the years 1995-2008, the Kibbutzim owned a commercial fish farm located in the north of the Gulf of Eilat. After a decade of fierce opposition from the city of Eilat and environmental organizations, a 2005 governmental decision ruled that the fish cages should be removed within three years. At the end of 2008 , the cages were evacuated, the Kibbutzim lost a lucrative agricultural industry, and the relationship between the two municipalities became very hostile.

Driven by the need to provide economic and social resilience to the Arava region, a strategic plan involving both municipalities (Eilat and Eilot) was written in 2002 by the head of the regional environmental unit. The plan was based on RE generation as a regional economic lever and set a production target of $100 \%$ RE electricity during the daytime by 2020 , intending to reach energy selfsufficiency by 2025 .

The 'Eilat-Eilot Renewable Energy' initiative began its activity as a department within the Eilot Regional Council in 2002, and by 2006, it became a separate entity. In 2012 it was established as a public benefit corporation which receives financial support from the city of Eilat and the Eilot Regional Council and is owned by the Kibbutzim and regional economic organizations.

At the end of 2020, 15 PV solar power plants varying in size with a total installed capacity of $190 \mathrm{MW}$ provided $100 \%$ of the region's electricity consumption during the day.

\section{Eilat-Eilot RE Initiative as a middle actor}


Eilat-Eilot Renewable Energy was initiated by and for the residents of the Arava region. Its board consists of public representatives and its purpose is to promote regional interests to strengthen the economy and social resilience. In the MOP terminology, Eilat-Eilot could be considered as a middle actor because it is positioned between the top and bottom actors and because it is perceived by the residents of the Arava region as a legitimate and trustworthy actor that represents the region's interests. Additionally, Eilat-Eilot, as described in the following section, aggregates physical assets, scientific and technical knowledge, and therefore has high levels of agency and capacity to support innovation in various ways. Ultimately, EilatEilot is shaping how energy is produced (by RE), consumed (as a promoter of regional macro-grid, that is an independent southern grid separated from the national grid), and stored (by providing demonstration sites for innovative storage technologies).

\section{Push and pull forces, the formation of an actor-network and the RE innovation ecosystem}

The findings of the analysis detailed below are presented in Figure 1. It illustrates the actors that joined the network during the years 2006-2020 and outlines the formation of the innovation ecosystem.

In 2002, commitment to the Kyoto protocol and aspiration to become a member of the OECD motivated Israel's government to pass its first decision regarding RE generation. The goals were modest, $5 \%$ by 2016 and $10 \%$ by 2020 with milestones of at least $2 \%$ of RE by 2007 , which should increase by an additional percentage every three years. These milestones were unrealistic given that no relevant policy or strategic plan were put in place to support them [91].

In 2007, five years after the milestone of producing 2\% RE by 2007 was set, the Israeli Government made no progress: no RE infrastructure had been developed, no quotas nor FiT have been set and no policies were issued to push RE generation [91]. In addition, the planning and construction system in Israel is the most centralized of all OECD countries. It is weighed heavily on the construction of RE facilities with lengthy bureaucratic procedures and over-regulation. These constitute significant barriers to the engagement of actors interested in promoting $\mathrm{RE}$ and low carbon transition, including Eilat-Eilot [79, 80]. With no ability to build RE generation facilities and with the understanding that it is necessary to pul/ the government to actively promote RE, Eilat-Eilot initiated and hosted the first Eilat-Eilot International Conference in mid-2007 with the title 'sustainable energy as a lever for regional development'. Threehundred participants attended the conference, which discussed Israel's RE policy, the available RE technologies in the region, as well as the barriers for RE implementation. The conference increased the visibility of Eilat-Eilot and raised awareness of the sustainable energy-related activities that were taking place in the region. Among the conference participants were the EU ambassador, decision-makers from the Ministry of Energy, energy experts from academia, and entrepreneurial companies. In addition to the conference, Eilat-Eilot, together with commercial companies, intensively lobbied within the parliament and government offices to pull the regulator to approve land allocation for medium and large RE facilities, to 
support RE pilot and demonstration projects, and to issue a governmental tender for the founding of a RE technology incubator in the Arava region.

Pulled by the Eilat-Eilot lobby, two governmental decisions were accepted during the years 2008-2009. The first was to issue a tender for the establishment of a RE technology incubator in the Negev and the Arava. The second decision was the recognition of the southern region of Israel as an area of national priority for the construction of RE generation facilities, with a specific reference to Eilot Regional Council. Pushed by Government's recognition, even though the Electricity Authority had not yet issued quotas for RE production, a local RE company (Arava Power Company, hereafter APC) signed collaboration agreements with 15 local Kibbutzim in the Negev and the Arava for the construction of RE facilities, with the support of Eilat-Eilot, which continued to pull the planning institutions for land allocation and the Electricity Authority for tariff regulation. These new stakeholders - the company and Kibbutzim - joined the Eilat-Eilot RE network, which grew and increased its ability to implement RE generation.

By the end of 2009, APC was granted the first license in Israel to build a 4MW solar PV field. In addition, the Electricity Authority approved three grid-connection licenses for an innovative RE pilot and demonstration facilities. Two of these are biogas plants located in northern Israel that produce electricity from organic waste, and the third is the first thermo-solar generation facility located in the Southern Arava. The thermo-solar pilot occupies two dunams with 30 consecutive mirrors (heliostats) and a 30 meter sun tower. The FiT for pilot and demonstration facilities did not cover all the production costs, and this was a small-scale and unprofitable facility (producing electricity for about 70 households). However, it enabled its founding company to present a valid 'proof of concept' project to potential customers worldwide, while strengthening the region's branding as a center for innovation.

Three major milestones were achieved by Eilat-Eilot in 2010, each expanded the network of actors which was created in the region and contributed to the RE implementation capabilities and the evolving RE innovation ecosystem:

First, pushed by the governmental tender for the establishment of a RE technology incubator, Eilat-Eilot established 'Capital Nature', an investment company aimed to nurture early-stage ventures with innovative sustainable technologies that address global challenges. Capital Nature's shareholders include well-established companies from the Israeli defense industry (such as Elbit and Refael), in addition to a large and well-known Israeli law firm, academic institutions from the southern part of the country (such as the Ben-Gurion University), venture capital funds, and the Eilot regional council and Eilat municipality. That year, 'Capital Nature' won the governmental tender for the establishment and management of the RE technology incubator in the Eilot Regional Council.

Second, APC's plan for the construction of the first large solar PV facility in Israel (40MW) in the Arava was submitted for statutory approval, although no official quota had yet been issued. Acknowledging that statutory procedures and the publication of quotas by the Electricity Authority are two lengthy bureaucratic procedures, APC assumed that both would be approved at the same time, and thus 
construction could begin. This act by APC, backed by the Eilat-Eilot RE network pulled the Electricity Authority to allocate quotas for large PV facilities.

Third, the Eilat-Eilot RE Conference was selected by the European Commission as one of the most influential conferences in the world and was included in the ECO4B project that supported international RE conferences in Spain, Slovenia, Bulgaria, and Italy during 2010-2011. The Eilat-Eilot conference received funding to subsidize the participation of high-profile delegations of investors, entrepreneurs, and large business entities, in order to create new networks and identify potential partnerships. This recognition increased the visibility and credibility of Eilat-Eilot to Israeli policymakers and the public and emphasized its uniqueness in the energy landscape, which was still heavily dominated by policies that support fossil fuel systems. The recognition helped Eilat-Eilot to reinforce its RE agenda and to promote a low carbon energy transition.

In 2011, Eilat-Eilot celebrated the operation of the first 4MW solar field in Israel, within the Southern Arava, which provided $3 \%$ of the total regional electricity consumption.

In 2012, with financial support from the Ministry of Energy and the Ministry of Economy, 'Capital Nature' inaugurated the first RE technology incubator in Israel, in the Eilot Regional Council. Clean-tech and energy-tech start-ups accepted to the incubator were committed to operate in the Arava for two years, during which they were provided with workspace free of charge, access to laboratories, and financial support. Capital Nature's experts provided guidance and mentoring services to the start-ups, assisted in identifying business opportunities, and established connections with potential investors. The incubator promoted various collaborations between the commercial sector and academic research institutions, thus extending and bolstering the network of stakeholders, while increasing its technological and financial capacities to foster innovation.

During this period, an experimental Off-grid Park was launched to test and demonstrate the applicability of various innovative technologies. The Park provided small and medium-sized enterprises (SMEs) the opportunity to prove the feasibility of technologies to support self-sufficiency and off-grid living.

During 2014, followed by the increase of RE quotas issued by the Electricity Authority, six solar fields in the Southern Arava were connected to the grid, in partnership with major international companies, among them EDF and Siemens. These attracted more investors to the growing network and further promoted the regional and national low-carbon energy system. Many public buildings in Eilat and Eilot were covered with solar PV panels and several Kibbutzim installed solar PV systems over the roofs of farm facilities, cowsheds, and communal buildings. At the end of this year, a total 70MW of RE energy facilities in the Southern Arava provided $35 \%$ of the total consumption of the Eilat and Eilot area and were responsible for $12 \%$ of national RE production. The government set milestone of $5 \%$ RE by 2014 was unmet, with only $590 \mathrm{MW}$ of RE installed, providing less than $2 \%$ of the national consumption.

In 2015, a $40 \mathrm{MW}$ solar field in the region was connected to the grid, increasing Eilat-Eilot installed RE capacity to $100 \mathrm{MW}$, which provided approximately $60 \%$ of the region's consumption. Adhering to its 
energy innovation vision, the incubator accepted companies that developed solutions for energy storage, off-grid technologies, and PV panel-cleaning robots to cope with desert dust. During this year, the city of Eilat won an EU grant and joined the "Green Neighborhoods" project that focused on reducing energy demand. Reducing demand and engaging the public in the transition to a low carbon energy system was one of the Eilat-Eilot goals and being added the RE network brought the vision of a carbon-free city closer. During this year, Eilat joined the 'Global Covenant of Mayors for Climate \& Energy', a global alliance for city climate leadership, and voluntarily committed to implementing the EU climate and energy objectives on its territory.

In 2016, the largest tender to date for the construction of a 60MW solar facility in Timna, the ancient mines in the Arava, was completed. Unlike other tenders managed by the Ministry of Energy, this tender involved the Israel Land Authority, because all the applicants also submitted bids for the land lease. Though the tender was supposed to be launched seven years earlier, it was postponed several times due to various objections coming from the Ministry of Finance, land allocation bureaucracy and procedures, delays in the work of the Electricity Authority, and four government changes. The price paid for the land was unprecedented, and Eilot Regional Council received a substantial share of it in exchange for the land. Most of the money was used to build a new off-grid elementary school. The use of RE revenues for the benefit of the public provided evidence that RE is a sustainable tool for regional development. During this year, the State of Israel ratified the Paris Agreement. While the modest commitment set in 2009 to produce 10\% RE in 2020 was left unchanged, Israel added a new target of 17\% RE generation by 2030 .

By 2017 Eilat-Eilot reached the milestone of $122 \mathrm{MW}$ of RE installed capacity, which provided $70 \%$ of the region's electricity consumption. However, the southern transmission infrastructure could no longer absorb any additional electricity production, hence it was not possible at this stage to construct additional large and medium solar facilities.

Following its vision to become a worldwide knowledge hub for the clean-tech sector, Eilat-Eilot established a professional training center, which hosts academic courses for undergraduate and graduate students in collaboration with the leading universities of Israel. Expanding the network to include students, lecturers, and researchers that discuss energy policy further pushed the interest of policymakers, investors, and businesses in promoting a low carbon transition. It also enriched the RE innovation ecosystem with young people and non-local actors and increased the network's range of influence.

In $\mathbf{2 0 1 8}$, to make solar production accessible to residents, the city of Eilat collaborated with a start-up from Capital Nature incubator in developing an application that provides residents with information regarding the feasibility and cost of installing solar panels on their roofs. With the financial support from the Israeli Innovation Authority, a software was developed to collect data from maps, photos, and weather forecast algorithms to evaluate the potential of solar electricity production on building rooftops, and to assess the financial viability in terms of economic savings and revenues. In addition, Eilat municipality issued a tender for rooftop solar system installers to provide residents with reliable suppliers that offer 
affordable financing options. Eilat was the first local government in Israel to simplify RE implementation by accessible means, thus making its residents active members in promoting regional energy selfsufficiency.

In 2020, the Ministries of Energy, Interior, and Environmental Protection published a "Guide to Installing Photovoltaic Systems in Local Government Assets". The guide referred to the order of operations, the mapping of a local government potential for solar installation, and relevant economic models. Given the strategic need to achieve government RE goals, while acknowledging Eilat-Eilot's experience, the Ministry of Energy with the Federation of Local Authorities supported the initiation of a practical course to be given at the Eilat-Eilot training center. The main purpose of the course was to assist local governments to follow the guide, and to provide tools for creating local sustainable strategies to promote social resilience. Officials from more than 20 local municipalities who participated in the course became agents of change within their municipality and joined the Eilat-Eilot vision while extending the RE network.

Connecting the additional 60MW solar facility in Timna at the end of 2020, brought Eilat-Eilot to a total of $190 \mathrm{MW}$ RE capacity. This amount accounted for $10 \%$ of the national RE production, and enabled EilatEilot to meet its goal of providing $100 \%$ of the regional electricity consumption by RE during the daytime. Israel, however, did not meet its target of $10 \%$ RE. Despite that, it updated its RE production target from $17 \%$ to $30 \%$ by 2030 , with a milestone of $20 \%$ by 2025 .

In 2021, pushed by the Ministry of Energy's call for funding energy storage pilots, a partnership was formed between a Kibbutz in the region and a company from 'Capital Nature' incubator. At the end of the year, a pilot of a $1 \mathrm{MW}$ compressed air storage system in the Arava had been constructed and tested. Committed to the target of becoming energy self-sufficient by 2025, the city of Eilat and the Eilot Region Council published a call for experts to obtain knowledge regarding solar energy storage technologies. The two municipalities, via Eilat-Eilot, are developing several projects to promote off-grid public buildings in their territories. In addition, the feasibility of developing a regional macro-grid (a separated southern electricity grid) is being examined in collaboration with the Ministry of Energy.

[1] The Arava region is a long, narrow valley located along Israel's south-eastern border. It begins south of the Dead Sea and extends to the Gulf of Aqaba

\section{Discussion}

This research followed the leading role that one middle actor - Eilat-Eilot - played in weaving a network of actors that aims to promote local sustainable development to achieve social and economic regional resilience. The analysis linked between Eilat-Eilot's establishment, development, and vision, the actions it took to accomplish its goals, the relations, and connections it formed with other actors, and the impact they had on the design and implementation of Israel's energy policy.

We applied a socio-technical perspective to the concepts of push and pull in order to determine the factors and actions that promoted RE supporting activities. We demonstrated how top actors 
(government ministries, regulators) were pulled to increase their levels of interest and engagement in promoting RE through policymaking and regulation, and how middle and bottom actors (organizations, firms, local entrepreneurs, local governments, citizens) were pushed to implement RE technologies. The analysis reflects how the push and pull forces can be expressed by social means, such as lobbying or call for action, and be influenced by public needs, social impact, and political agenda.

The findings demonstrate the middle actors' capacity to link top actors (the Innovation Authority, government ministries), middle actors (venture capital, law firms, academic institutions, high-tech companies, and municipalities), and bottom actors (entrepreneurs, start-ups, local settlements) with diverse interests in complex yet meaningful interactions. The findings also highlight the central role that Eilat-Eilot played in adding actors to the RE network, in establishing the RE innovation ecosystem, and in shaping Israel's energy policy. These findings fit well with the innovation literature notion that innovation emerges in co-evolutionary interactions between diverse actors and various needs for change [92]. They also support the notion that innovation ecosystems fulfill various purposes, such as knowledge sharing, idea development, access to financial resources, or approach to new markets, and are not restricted to a single sector or specific technology [93].

Previous studies that applied the MOP as an analytical perspective focused on three middle out modes of action - aggregation, mediation, and enabling - and on the levels of actors' agency and capacity, as variables that affect the course and magnitude of change $[48,55,61,62]$. Only a few studies have focused on the sideway impact and have closely examined the roles that middle actors play in the formation of networks $[48,56]$. Here we focused on the balance of power between the various actors in the arena, and on how actors are pushed to use their capabilities to act or pulled to increase their level of agency and become actively involved in a network of actors that form an innovation ecosystem. As such, this research contributes toward a more comprehensive understanding of the middle out mechanisms of change.

In the current state of affairs, it is unlikely that Israel will meet its 2030 RE production targets unless major action is taken. Often, large-scale actions are thwarted by policies at the national level. This happens because policymakers tend to keep actors such as local governments unengaged, which makes them unable to implement policies in an adequate manner [94]. Decentralization and a deliberate delegation of power from the central government to networks of actors that include middle actors with various enabling capabilities would likely increase the number of engaged stakeholders and improve implementation rates.

While this research presents a case study from Israel, its insights are relevant to other countries. Nearly half of the European continent is considered rural and is identified as lacking job opportunities and public services, as well as access to health care services, and good education [95]. Place-based innovation promoted by the new EU Green Deal relies on local governance to drive regional and local innovation to enhance sustainable growth and to increase regional resilience [49]. Middle actors at the local level often have the capacity to strengthen relationships amongst actors, lead change, exchange knowledge and 
pave the way for professional collaborations and innovation networks that involve community members. These networks have the potential to lead innovative solutions for problems related to public health, energy and water storage, climate resiliency, initiate research, encourage investments, create employment possibilities, and promote regional sustainable development.

\section{Conclusions}

This paper analyses the case of Israel's RE innovation ecosystem creation through the lens of the MiddleOut Perspective. It applies a socio-technical interpretation to the push and pull terminology and demonstrates how middle actors push the implementation of RE technologies in Israel, and at the same time pull decision-makers and other middle actors to promote the low carbon transition. The push and pull forces and the interactions between actors lead to the engagement of new stakeholders in the innovation network, the adoption of more ambitious RE targets and supporting policies, and to the creation of an effective RE innovation ecosystem.

\section{Declarations}

\section{Ethics approval and consent to participate}

Not applicable

\section{Consent for publication}

Not applicable

\section{Availability of data and materials}

The authors confirm that the empirical data from the study support the findings and are available within the paper. The transcripts of all interviews are available in Hebrew and can be accessed from the corresponding author upon reasonable request

\section{Competing interests}

Not applicable

\section{Funding}

This study was supported by Israel Science Foundation (ISF grant no. 184542).

\section{Authors' contributions}

All authors have agreed to the published version of the manuscript. All authors read and approved the final manuscript. 
Acknowledgements

Not applicable

\section{References}

1. King S (2016) Biggest opportunity of our age. Science (80- ) 351:107. https://doi.org/10.1126/SCIENCE.AAF1428

2. Diercks G, Larsen H, Steward $F$ (2019) Transformative innovation policy: Addressing variety in an emerging policy paradigm. Res Policy 48:880-894. https://doi.org/10.1016/J.RESPOL.2018.10.028

3. Frank AG, Gerstlberger W, Paslauski CA, et al (2018) The contribution of innovation policy criteria to the development of local renewable energy systems. Energy Policy 115:353-365. https://doi.org/10.1016/J.ENPOL.2018.01.036

4. Gielen D, Boshell F, Saygin D, et al (2019) The role of renewable energy in the global energy transformation. Energy Strateg Rev 24:38-50. https://doi.org/10.1016/J.ESR.2019.01.006

5. Kittner N, Lill F, Kammen DM (2017) Energy storage deployment and innovation for the clean energy transition. Nat Energy 2:. https://doi.org/10.1038/nenergy.2017.125

6. Schönberger P (2013) Municipalities as key actors of German renewableenergy governance: An analysis of opportunities,obstacles, and multi-level influences

7. Rennings K (2000) Redefining innovation - Eco-innovation research and the contribution from ecological economics. Ecol Econ 32:319-332. https://doi.org/10.1016/S0921-8009(99)00112-3

8. Tidd J (2006) Innovation Models

9. Liddle S, El-Kafafi S (2010) Drivers of sustainable innovation push, pull or policy. World J Entrep Manag Sustain Dev 6:. https://doi.org/10.1108/20425961201000022

10. Horbach J, Rammer C, Rennings K (2012) Determinants of eco-innovations by type of environmental impact - The role of regulatory push/pull, technology push and market pull. Ecol Econ 78:112-122. https://doi.org/10.1016/J.ECOLECON.2012.04.005

11. Dosi G (1982) Technological paradigms and technological trajectories. A suggested interpretation of the determinants and directions of technical change. Res Policy 11:. https://doi.org/10.1016/00487333(82)90016-6

12. Zmud RW (1984) An Examination of "Push-Pull" Theory Applied to Process Innovation in Knowledge Work. Manag Sci 30:727-738

13. Lennon B, Dunphy NP, Sanvicente E (2019) Community acceptability and the energy transition: a citizens' perspective. Energy, Sustain Soc 201991 9:1-18. https://doi.org/10.1186/S13705-0190218-Z

14. Sütterlin B, Siegrist M (2017) Public acceptance of renewable energy technologies from an abstract versus concrete perspective and the positive imagery of solar power. Energy Policy 106:356-366. https://doi.org/10.1016/J.ENPOL.2017.03.061 
15. Borrás S (2004) Introduction to special issue on a European system of innovation. Sci Public Policy 31:422-424. https://doi.org/10.3152/147154304781779750

16. Edquist C (1997) Systems of innovation: Technologies. Institutions Organ Pinter, London 1-35

17. Carlsson B, Jacobsson S, Holmen M, Rickne A (2002) Innovation systems: Analytical and methodological issues. Res Policy 31:233-245. https://doi.org/10.1016/S0048-7333(01)00138-X

18. Nelson RR, Nelson K (2002) Technology, institutions, and innovation systems. Res Policy 31:265272. https://doi.org/10.1016/S0048-7333(01)00140-8

19. Nelson RR (1993) National innovation systems: a comparative analysis . Oxford University Press on Demand

20. Lundvall B-Å (1992) National systems of innovationtowards a theory of innovation and interactive learning. Towards a theory of innovation and interactive learning

21. Edquist C (2004) Reflections on the systems of innovation approach. Sci Public Policy 31:485-489

22. Edler J, Kuhlmann S, Smits R (2003) New governance for innovation: The need for horizontal and systemic policy co-ordination

23. Autio E, Thomas LDW (2014) Innovation Ecosystems. The Oxford handbook of innovation management

24. Augusto L, Gomes V, Lucia A, et al (2018) Unpacking the innovation ecosystem construct: Evolution, gaps and trends. Technol Forecast Soc Chang 136:30-48.

https://doi.org/10.1016/j.techfore.2016.11.009

25. Jackson DJ (2011) What is an innovation ecosystem. Natl Sci Found 1:1-13

26. Moore JF (1993) Predators and prey: a new ecology of competition. Harvard Bus Rev 71:75-86

27. Borrás S, Edquist C (2019) Why we need an holistic innovation policy: Goals, problems and instruments. In: Holistic innovation policy: theoretical foundations, policy problems, and instrument choices

28. Blyth W, Bradley R, Bunn D, et al (2007) Investment risks under uncertain climate change policy. Energy Policy 35:5766-5773. https://doi.org/10.1016/j.enpol.2007.05.030

29. Kivimaa P, Kern F (2016) Creative destruction or mere niche support? Innovation policy mixes for sustainability transitions. Res Policy 45:205-217. https://doi.org/10.1016/J.RESPOL.2015.09.008

30. Taylor M (2008) Beyond technology-push and demand-pull: Lessons from California's solar policy. Energy Econ 30:2829-2854. https://doi.org/10.1016/j.eneco.2008.06.004

31. Pitelis A, Vasilakos N, Chalvatzis K (2020) Fostering innovation in renewable energy technologies: Choice of policy instruments and effectiveness. Renew Energy 151:1163-1172. https://doi.org/10.1016/j.renene.2019.11.100

32. Komor P, Bazilian M (2005) Renewable energy policy goals, programs, and technologies. Energy Policy 33:1873-1881. https://doi.org/10.1016/j.enpol.2004.03.003

33. Alic J, Sarewitz D, Weiss C, Bonvillian W (2010) A new strategy for energy innovation. Nature 466: https://doi.org/https://doi-org.ezproxy.haifa.ac.il/10.1038/466316a 
34. Peters M, Schneider M, Griesshaber T, Hoffmann VH (2012) The impact of technology-push and demand-pull policies on technical change - Does the locus of policies matter? Res Policy 41:12961308. https://doi.org/10.1016/J.RESPOL.2012.02.004

35. Horbach J, Rammer C, Rennings K (2012) Determinants of eco-innovations by type of environmental impact - The role of regulatory push/pull, technology push and market pull. Ecol Econ 78:112-122. https://doi.org/10.1016/j.ecolecon.2012.04.005

36. Suurs RAA, Hekkert MP (2009) Cumulative causation in the formation of a technological innovation system: The case of biofuels in the Netherlands. Technol Forecast Soc Change 76:1003-1020. https://doi.org/10.1016/J.TECHFORE.2009.03.002

37. Bäckstrand K, Kuyper JW, Linnér B-O, Lövbrand E (2017) Environmental Politics Non-state actors in global climate governance: from Copenhagen to Paris and beyond.

https://doi.org/10.1080/09644016.2017.1327485

38. Kuyper JW, Linnér B-O, Schroeder H (2018) Non-state actors in hybrid global climate governance: justice, legitimacy, and effectiveness in a post-Paris era. Wiley Interdiscip Rev Clim Chang 9:e497. https://doi.org/10.1002/wcc.497

39. Matsumoto T, Allain-Dupré D, Crook J, Robert A (2019) An integrated approach to the Paris climate Agreement: The role of regions and cities. https://doi.org/10.1787/96b5676d-en

40. Warbroek B, Hoppe T (2017) Modes of governing and policy of local and regional governments supporting local low-carbon energy initiatives; exploring the cases of the dutch regions of Overijssel and Fryslân. Sustain 9:. https://doi.org/10.3390/su9010075

41. Arentsen M, Bellekom S (2014) Power to the people: Local energy initiatives as seedbeds of innovation? Energy Sustain Soc 4:1-12. https:// doi.org/10.1186/2192-0567-4-2/FIGURES/3

42. Krozer $Y$ (2017) Innovative offices for smarter cities, including energy use and energy-related carbon dioxide emissions. Energy Sustain Soc 7:1-13. https://doi.org/10.1186/S13705-017-01045/TABLES/9

43. Aust HP (2019) The shifting role of cities in the global climate change regime: From paris to pittsburgh and back? Rev Eur Comp Int Environ Law 28:57-66. https://doi.org/10.1111/reel.12272

44. Hale T (2016) "All Hands on Deck": The Paris Agreement and Nonstate Climate Action . Glob Environ Polit 16:12-22. https://doi.org/10.1162/GLEP_a_00362

45. Süsser D, Döring M, Ratter BMW (2017) Harvesting energy: Place and local entrepreneurship in community-based renewable energy transition. Energy Policy 101:332-341. https://doi.org/10.1016/j.enpol.2016.10.018

46. Janda KB, Parag Y (2013) A middle-out approach for improving energy performance in buildings. Build Res Inf 41:39-50. https://doi.org/10.1080/09613218.2013.743396

47. Parag Y, Janda KB (2014) More than filler: Middle actors and socio-technical change in the energy system from the "middle-out." Energy Res Soc Sci 3:102-112. https://doi.org/10.1016/j.erss.2014.07.011 
48. Zohar T, Parag Y, Ayalon O (2021) Of agency, action, and influence: The middle-out mechanism for promoting a low-carbon energy transition. Energy Res Soc Sci 72:101900. https://doi.org/10.1016/j.erss.2020.101900

49. McCann P, Soete L (2020) Place-based innovation for sustainability. Luxembourg

50. Hufen JAM, Koppenjan JFM (2015) Local renewable energy cooperatives: revolution in disguise? Energy, Sustain Soc 201551 5:1-14. https://doi.org/10.1186/S13705-015-0046-8

51. Janda KB, Reindl K, Blumer Y, et al (2019) Making more of middles: Advancing the middle-out perspective in energy system transformation. Eceee Summer Study Proc 2019-June:199-204

52. Khosla R, Janda KB (2019) India's building stock: towards energy and climate change solutions. Build Res Inf 47:1-7

53. Janda K, Killip G, Fawcett T (2014) Reducing Carbon from the "Middle-Out": The Role of Builders in Domestic Refurbishment. Buildings 4:911-936. https://doi.org/10.3390/buildings4040911

54. Reindl K, Palm J (2020) Energy efficiency in the building sector: a combined middle-out and practice theory approach. Int J Sustain Energy Plan Manag 3-16

55. Kranzler Y, Parag Y, Davidovitch N (2019) Public health from the middle-out: A new analytical perspective. Int J Environ Res Public Health 16:. https://doi.org/10.3390/ijerph16244993

56. Zohar T, Parag Y, Ayalon O (2020) Strategizing demand management from the middle out: Harnessing middle actors to reduce peak electricity consumption. Energy Res Soc Sci 61:101360. https://doi.org/10.1016/j.erss.2019.101360

57. Frick V, Seidl R, Stauffacher M, Moser C (2017) Promoting energy-saving behaviour: formal social groups as promising middle actors for municipal interventions. 1539-1551. https://doi.org/10.1007/s12053-017-9543-2

58. Cauvain J, Karvonen A (2018) Social housing providers as unlikely low-carbon innovators. Energy Build 177:394-401. https://doi.org/10.1016/j.enbuild.2018.08.012

59. Owen A, Heppenstall A (2018) Making the case for simulation: Unlocking carbon reduction through simulation of individual 'middle actor' behaviour. Environ Plan B Urban Anal City Sci. https://doi.org/10.1177/2399808318784597

60. Goulden M, Spence A (2015) Caught in the middle: The role of the Facilities Manager in organisational energy use. Energy Policy 85:280-287. https://doi.org/10.1016/j.enpol.2015.06.014

61. Parag Y, Zur S, Raz N (2017) Levels of consumers' agency and capacity as predictors for electricity demand reduction in the residential sector. Energy Effic 10:597-611. https://doi.org/10.1007/s12053-016-9471-6

62. Parag Y, Janda K (2010) A Middle-Out Approach to Agency, Capacity and Societal Change BIEE Conference, Sep 2010, Oxford. EciOxAcUk 1-13

63. Repo F, Ess ST, Ess ST, Security ES Final Repo it Summary - ST ESS ( ST ESS: So cio -T echnical and multilevel perspectives o n Energy Services Security ) Co ntact. 4-6. https://doi.org/10.1038/NENERGY.2016.32.Parag 
64. Wade F, Hitchings R, Shipworth M (2016) Understanding the missing middlemen of domestic heating: Installers as a community of professional practice in the United Kingdom. Energy Res Soc Sci 19:39-47. https://doi.org/10.1016/j.erss.2016.05.007

65. Darby SJ (2020) Demand response and smart technology in theory and practice: Customer experiences and system actors. Energy Policy 143:111573. https://doi.org/10.1016/j.enpol.2020.111573

66. Palm J, Reindl K (2018) Understanding barriers to energy-efficiency renovations of multifamily dwellings. Energy Effic 11:53-65. https://doi.org/10.1007/s12053-017-9549-9

67. Zohar T, Parag Y, Ayalon O (2020) Strategizing demand management from the middle out: Harnessing middle actors to reduce peak electricity consumption. Energy Res Soc Sci 61: https://doi.org/10.1016/j.erss.2019.101360

68. The Electricity Autority (2020) Report on the State of the Electricity Sector | 2020

69. UNFCCC Website National Inventory 2018 - Israel. https://unfccc.int/documents/254583. Accessed 7 Nov 2021

70. Tal A (2020) Israel Can Do Better: A 70-Year Report Card of Environmental Underachievement. Tel Aviv Rev Books

71. OECD (2020) Accelerating Climate Action in Israel: Refocusing Mitigation Policies for the Electricity, Residential and Transport Sectors. OECD Publishing, Paris

72. Shaffer B (2011) Israel-New natural gas producer in the Mediterranean. Energy Policy 39:53795387

73. Wolfson A, Ayalon O, Tal A (2020) A Strategic Analysis of National Electricity Generation Alternatives: A Perspective from the Future. J Environ Sci Public Heal 04: https://doi.org/10.26502/jesph.96120100

74. Tal A (2020) Unkept Promises: Israel 's Implementation of Its International Climate Change Commitments Unkept Promises: Israel 's Implementation of Its International Climate Change Commitments. 20-51. https://doi.org/10.1080/23739770.2020.1749965

75. Ayalon O, Brokovich E, Yair Y, et al (2016) Opinion of the Israeli Association of Ecology and Environmental Sciences on the Paris Agreement 2015 for Reducing Greenhouse Gas Emissions and Preparing for Climate Change

76. Bank of Israel-Reserach Divison (2015) The use of renewable energy in Israel

77. Michaels L, Tal A (2015) Convergence and co flict with the 'National Interest': Why Israel abandoned its climate policy. Energy Policy 87:480-485. https://doi.org/10.1016/j.enpol.2015.09.040

78. Bank of Israel-Reserach Divison (2017) Anthology of policy analysis and research issues

79. Alterman R, Teschner N (2019) Grounded renewable energy: land and planning-related barriers in Israel in comparative view

80. Knesset Israel-Research and Information Center (2020) Renewable energy in Israel - background and issues for discussion 
81. Gal N, Reshef B (2021) 1000 megawatts in 5 steps: Outline for accelerating the connection of renewable energy facilities to the grid

82. Navon A, Kulbekov P, Dolev S, et al (2020) Integration of distributed renewable energy sources in Israel: Transmission congestion challenges and policy recommendations. Energy Policy 140:111412. https://doi.org/10.1016/j.enpol.2020.111412

83. Ben Yosef G, Navon A, Poliak O, et al (2021) Frequency stability of the Israeli power grid with high penetration of renewable sources and energy storage systems. Energy Reports 7:6148-6161. https://doi.org/10.1016/J.EGYR.2021.09.057

84. Fortuna G, Freund-Koren S, Liebes I (2015) Renewable Energy and Energy Efficiency Industry in Israel: Update and policy recommendations for leveraging Israeli R\&D and industry. Haifa, Israel

85. Collier D (2011) Understanding Process Tracing. PS Polit Sci Polit 44:823-830. https://doi.org/10.1017/S1049096511001429

86. Mahoney J (2012) The Logic of Process Tracing Tests in the Social Sciences. Sociol Methods Res 41:570-597. https://doi.org/10.1177/0049124112437709

87. Beach D (2016) It's all about mechnisms what process-tracing case studies should be tracing. New Polit Econ 21:463-472. https://doi.org/10.1080/13563467.2015.1134466

88. Ricks JI, Liu AH (2018) Process-Tracing Research Designs: A Practical Guide. PS - Polit Sci Polit 51:. https://doi.org/10.1017/S1049096518000975

89. Trampusch C, Palier B (2016) Between $X$ and $Y$ : how process tracing contributes to opening the black box of causality. New Polit Econ 21:. https://doi.org/10.1080/13563467.2015.1134465

90. Bennett A, Elman C (2007) Case study methods in the international relations subfield. Comp Polit Stud 40:. https://doi.org/10.1177/0010414006296346

91. Robas I (2008) Regulatory barriers for adopting renewable energy in Israel

92. Avelino F, Wittmayer JM, Pel B, et al (2019) Transformative social innovation and (dis)empowerment. Technol Forecast Soc Change 145:195-206. https://doi.org/10.1016/J.TECHFORE.2017.05.002

93. Araújo R, Franco M (2021) The use of collaboration networks in search of eco-innovation: A systematic literature review. J Clean Prod 314:127975.

https://doi.org/10.1016/J.JCLEPRO.2021.127975

94. Shefer I (2020) German and Israeli Cities at the Intersection of Tech Innovation and Decarbonization: Trends and Challenges. Policy Pap Ser "Decarbonization Strateg Ger Isr Potsdam/Tel Aviv Inst Adv Sustain Stud (IASS), Isr Public Policy Inst (IPPI), Heinrich-Böll-Stiftung Tel Aviv. https://doi.org/10.2312/iass.2020.042

95. Lombardi M, Lopolito A, Andriano AM, et al (2020) NETWORK IMPACT OF SOCIAL INNOVATION INITIATIVES IN MARGINALISED RURAL COMMUNITIES. Soc Networks 63:11-20. https://doi.org/10.1016/J.SOCNET.2020.04.001

\section{Figures}




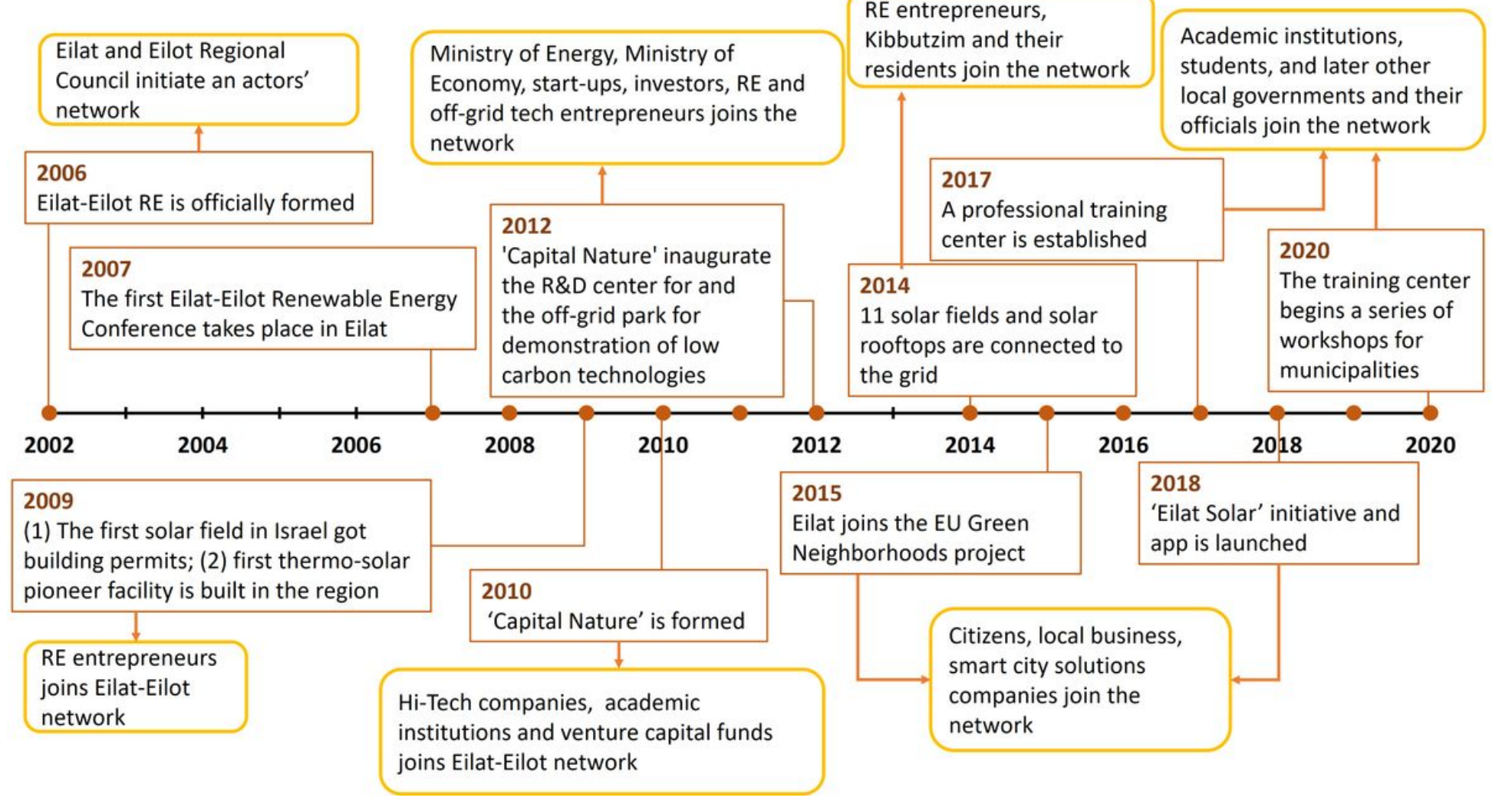

\section{Figure 1}

\section{Eilat-Eilot RE actors-network}

